\title{
Prostatic Epithelium
}

National Cancer Institute

\section{Source}

National Cancer Institute. Prostatic Epithelium. NCI Thesaurus. Code C13103.

Tissue composed of one or more layers of epithelial cells and a basement membrane. It lines the secretory alveoli and secretory ducts of the prostate. The secretory epithelium consists mostly of pseudostratified columnar cells and basal cells with areas of cuboidal and squamous epithelial cells. The walls of the prostatic urethra and the distal regions of the longer ducts are lined with transitional epithelium. 